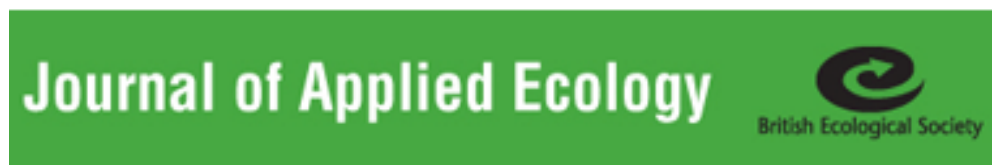

\title{
Assessing different management scenarios to reverse the declining trend of a relict capercaillie population: a modeling approach
}

\begin{tabular}{|r|l|}
\hline Journal: & Journal of Applied Ecology \\
\hline Manuscript ID: & Draft \\
\hline Manuscript Type: & Standard Paper \\
\hline Date Submitted by the & $\mathrm{n} / \mathrm{a}$ \\
\hline Complete List of Authors: & $\begin{array}{l}\text { Fernández-Olalla, Mariana; ETSI Montes. Universidad Politecnica de } \\
\text { Madrid, Silvopascicultura } \\
\text { Martínez-Abraín, Alejandro; IMEDEA (CSIC-UIB), Population } \\
\text { Ecology Group } \\
\text { Canut, Jordi; Parc Nacional d'Aigüestortes i Estany de Sant Maurici. } \\
\text { Departament de Medi Ambient i Habitatge } \\
\text { García-Ferré, Diego; Servei de Protecció de la Fauna, Flora i } \\
\text { Animals de Companyia. Departament de Medi Ambient i Habitatge } \\
\text { Afonso, Ivan; Asociación para la Conservación del Urogallo } \\
\text { González, Luis Mariano; Ministerio de Medio Ambiente y Medio Rural } \\
\text { y Marino, Subdirección General de Biodiversidad. Dirección General } \\
\text { del Medio Natural y Política Forestal }\end{array}$ \\
\hline Key-words: & $\begin{array}{l}\text { capercaillie, captive-breeding , evidence-based conservation, } \\
\text { habitat management, population viability analysis, predation } \\
\text { management, predator removal, Tetrao urogallus }\end{array}$ \\
\hline \hline
\end{tabular}

\section{SCHOLARONE ${ }^{\mathrm{m}}$ Manuscripts}


Running title: Conservation of a relict capercaillie population

\section{Assessing different management scenarios to reverse the declining trend of a relict capercaillie population: a modeling approach}

Fernández-Olalla, Mariana ${ }^{1 *}$; Martínez-Abraín, Alejandro ${ }^{2}$; Canut, Jordi ${ }^{3}$; García-Ferré, Diego $^{4}$; Afonso I ${ }^{5}$; González, Luis Mariano ${ }^{6}$

1. Dep. Silvopascicultura, ETSI de Montes, UPM, C/Ciudad Universitaria, s/n, 28040 Madrid, Spain. E-mail: mariana.fernandez@upm.es; telephone number: +34-915336414; fax number: +34-915439557.

* Corresponding author

2. IMEDEA (CSIC-UIB). Population Ecology Group. C/Miquel Marquès 21, 07190

Esporles, Mallorca, Spain. E-mail: amartinez@imedea.uib-csic.es

3. Parc Nacional d'Aigüestortes i Estany de Sant Maurici. Departament de Medi Ambient i Habitatge. C/ Prat del Guarda 4, 25597 Espot (Lleida). Tfno: 650952197. E-mail: jcanut@gencat.cat

4. Servei de Protecció de la Fauna, Flora i Animals de Companyia. Departament de Medi Ambient i Habitatge. C/ Dr Roux 80, 08017 Barcelona. E-mail: adgarfe@gencat.cat

5. Asociación para la Conservación del Urogallo (ACU) y MUSIA SCP. C/ Gramenet 3, 25510 La Plana (Lleida). E-mail: ivan@musia.cat

6. Subdirección General de Biodiversidad. Dirección General del Medio Natural y Política Forestal. Ministerio de Medio Ambiente y Medio Rural y Marino. C/ Ríos Rosas 24, 28003 Madrid. E-mail: 1mgonzalez@mma.es

Number of words: Summary=349; Main text $=5260 ; \quad$ Acknowledgements $=111$;

References $=1419 ;$ Table legends $=202 ;$ Figure legends $=170$

Number of tables $=4 ;$ Number of figures $=5 ;$ Number of references $=55$ 


\section{Summary}

1. Capercaillie populations are declining in most of its distribution area. In almost none of its populations the regressive trend can be explained by only one main cause but there are several interacting ones, whose effects are not easy to disentangle. Thus, often wildlife conservationists have to make decisions based on poor evidence.

2. This study analyzes the trend of the relict capercaillie population in the Spanish Pyrenees on the basis of bird densities estimated throughout the period 1989-2010, and constitutes the first attempt to modelling the dynamics of a capercaillie population in southern Europe. 3. We also explored two management actions commonly used to enhance endangered prey species, thought to be affected by hyperpredation: the release of captive-bred females, in varying numbers, the removal of terrestrial meso-carnivores and the combination of both actions, using available information from a past experience of captive breeding and from an ongoing experience of terrestrial meso-predator removal.

4. The population was declining at an annual rate of $4 \%$ for the last 20 years. Sensitivity analysis showed that recruitment (productivity+fledgling survival), rather than adult survival, was the demographic parameter which most likely could be increased by management.

5. The removal of terrestrial meso-carnivores may lead to the stabilization of the capercaillie population (lambda $0.99 \pm 0.06$ ), although this result should be considered as preliminary. To be conservative, the only effective strategy was the combination of mesopredator removal in combination with the release of either 15,30 or 45 adult females per year.

5. Synthesis and applications. We recommend to implement these urgency measures together with other complementary actions, as a more efficient long-term conservation 
strategy. The control of wild ungulate numbers, in the absence of top predators, and the removal of carcasses generated by hunting activity may lead to the self-regulation of the meso-predator guild. Decreased densities of ungulates may also prevent damages in bilberry cover, a basic resource for the species. Additionally, habitat management practices, such as the thinning of the currently encroaching tree stands, after massive depopulation of rural areas, should also be considered, for its possible role on predation rates and bilberry persistence.

Key-words: capercaillie, captive-breeding, evidence-based conservation, habitat management, population viability analysis, predation management, predator removal, Tetrao urogallus. 


\section{Introduction}

The southern European peninsulas housed many boreal species which were isolated there after the retreat of the ice sheet originated during the last glacial period of the Pleistocene (Hewitt 1999). These marginal populations are known to be more prone to extinction and genetically impoverished, as they tend to occur in less favourable habitats and at lower and more variable densities (Vucetich \& Waite 2003). Predation may compromise the persistence of such isolated populations, in the case of prey species (Macdonald, Mace \& Barretto. 1999).

Although many studies have demonstrated that predators may affect considerably only those prey populations which are under unfavorable conditions (Genovart et al. 2010) (i.e. predation as a compensatory factor), many authors have stated that predators can, at least, limit prey populations under a wide range of situations (Connolly 1978; Sinclair et al. 1998) (i.e. predation as an additive factor). Hyperpredation refers to situations with an enhanced predation impact on an alternative prey due to an increase in predator numbers caused by either a rapid increase or a sudden drop in the abundance of its main prey (Moleón, Almaraz \& Sanchez-Zapata 2008). Unintended supplementary feeding or subsidization of predators by human activities (i.e. landfills, hunting and fishing remains) may play the same role of an increase in the abundance of their alternative preys, leading to a numerical response by predators that can drastically impact prey populations, especially when those are in low numbers (Gompper \& Vanak 2008).

To alleviate the effect of predation on vulnerable prey many possible management strategies may be proposed, but all of them should consider both the whole assemblages of predators and alternative prey. The restoration of the original top predator community (Gompper \& Vanak 2008), the elimination of subsidization sources for predators (Bino et 
al. 2010; Tablado et al. 2010) or the improvement of shelter availability within prey habitat (Evans 2004; Lombardi, Fernández \& Moreno 2007), have been widely invoked in conservation programs. Although these strategies are more advisable because they aim the long-term continued increase or recovery of the target species, often other shorter-term strategies are carried out, sometimes because it is necessary to gain years before addressing the roots of the problem (Igual et al. 2009), but often also because they are more visible to the donating public (Ludwig, Mangel \& Haddad 2001). Two of the most widespread examples of these "hard" strategies are predator control and the translocation or release of captive-bred individuals. However, both strategies may be controversial, due to ethical and practical problems (e.g. Beck 1995; Reynolds \& Tapper 1996; Smith et al. 2010).

The positive effects of predator control tend not to be maintained over time, because density-dependent buffering processes tend to counter-balance the effect of removals (see e.g. Bosch et al. 2000; Smith et al. 2010). In addition, most studies have evaluated the effect of predator removal in terms of improved breeding success, although, it has seldom been assessed whether the associated increase in productivity actually represents a relevant effect on the growth rate of the prey population (Fletcher et al. 2010; Lavers, Wilcox \& Donlan 2010). In relation to reintroduction of captive-reared wildlife, this technique has experienced increased popularity recently (Seddon, Armstrong \& Maloney 2007). However, the success of these programs may be low when the causes of the original decline have not been reversed at the moment of the release or because captive-reared animals have not had previous exposure to local predators or food sources in the wild (Snyder et al. 1996; Wolf, Garland \& Griffith 1998, Fischer \& Lindenmayer 2000).

In this paper, we analyse the trend of a relict population of a ground-nesting prey species, the capercaillie (Tetrao urogallus) in the Pyrenees Mountains, classified as 
"vulnerable" under the Spanish law. We examine different management scenarios to enhance population trend, using a population modeling approach, in an attempt to deal with the uncertainty that involves its management. We use an integrative procedure, which combines field monitoring data for more than 20 years and simulations, which accounts for environmental stochasticity. Specifically, we explore the effects of the release of captivebred birds and of the removal of terrestrial meso-predators on capercaillie population, as it is suspected that predation may be aggravating the situation of this isolated population, due to multiple and complex anthropogenic changes in a high-mountain environment. We have worked within an adaptive management framework, using available information from a past experience of captive breeding and from an ongoing experience of terrestrial mesopredator removal, to ensure that models reflect realistic management options and applying the precautionary principle.

\section{Materials and methods}

\section{Study population and monitoring data}

Capercaillie (Tetrao urogallus) is the greater grouse species in Europe and has been proposed as an 'umbrella' species (Suter, Graf \& Hess 2002). Two of the twelve subspecies described for the species (T. u. cantabricus and T. u. aquitanus) are present in the Iberian Peninsula. Both populations are located in the southernmost edge of their world distribution, and are geographically isolated both among them and with respect to the other European populations. More than the $80 \%$ of the known leks of Pyrenean capercaillie are located in Catalonia, north-eastern Iberian Peninsula (Robles, Ballesteros \& Canut 2006). The estimated number of males at leks has decreased by $31 \%$ in Catalonia since the early 
90s (op. cit.). The study population is located in the Pallars Sobirà region, which accounts for $35 \%$ of the known leks in Catalonia. Most of the study area is included in the Alt Pirineu Natural Park. The species mainly inhabits subalpine forests, located between 1500 and $2000 \mathrm{~m}$ a.s.1. They are dominated by mountain pine (Pinus uncinata), usually with a bilberry and rhododendron (Rhododendron ferrugineum) shrub cover.

Empirical data consisted on "route censuses" (Leclercq 1987) from the summer monitoring program carried out by the Catalonian environmental agency since 1988. Censuses consists on a line transect of 4-14 people arranged at $10 \mathrm{~m}$ intervals walking simultaneously through forest patches. By the time of the census, chicks are well grown and most of them are able to fly, so hereafter we will call them "fledglings". The number of flushed males, females and fledglings is recorded, as well as the surface covered by each census. Undetermined birds are omitted from demographic parameters calculations. The number of people who has participated in each field day exceeds 100 people per year, since 1988.

\section{Empirical estimation of population trend}

Density of adult birds (birds/100 has) was estimated by dividing the number of adult males and females by the surface covered by each census. Annual density was calculated as the mean value of all the densities of the censuses carried out each year. This is the first occasion in which the available time series of summer counts has been compiled to estimate the trend of the Spanish Pyrenean population. Nevertheless, the use of this type of density data to estimate population trends is common in other countries (see Lecqlerq 1987). The total surface covered every year may affect the validity of the density estimates obtained, leading to non-representative estimates in those years in which the sampling effort was low 
due to logistic limitations. Preliminary linear regressions of density estimates with the surface covered each year, determined that the minimum surface sampled to obtain density estimates independent of surveying effort was 450 hectares.

We used population densities from 1989 to 2010 , duly filtered ( $\mathrm{n}=17$ years), to estimate the population growth rate. The finite annual population growth rate or deterministic growth rate $(\lambda)$ was calculated considering that $\mathrm{N}_{\mathrm{t}}$ (the population size at time t) asymptotically is proportional to $\mathrm{N}_{0} \lambda^{\mathrm{t}}$, and hence estimated $\lambda$ is $\lambda=\left(\mathrm{N}_{\mathrm{t}} / \mathrm{N}_{0}\right)^{1 / \mathrm{t}}$. Finally, to analyse the population trend, we performed a linear regression of population density and time to obtain the $95 \%$ confidence interval for the slope of the regression line. We tested the null hypothesis of population stability by checking whether the $95 \%$ confidence interval of the slope bracketed the value zero or not.

\section{Simulated trend: modelling approach}

Our modelling approach used a stage-structured matrix population model to simulate the retrospective growth of the population between 1989 and 2010. We considered only one sex (females) and two age classes: fledglings (for birds less than one year old) and adults (thereafter) due to the lack of more structured information (Figure 1). We assumed, as in previous modelling approaches for the species (Sachot, Perrin \& Neet 2006), that males are not the limiting sex in lekking species. Hence, to parameterize the model we needed three vital rates: number of daughters per adult female in the population (hereafter, productivity Prod), survival of fledgling females $\left(S_{F l}\right)$ and survival of adult females $\left(S_{A d}\right)$. We ran 1000 replications of what we defined as our baseline model (see below) for a 22 years period with an annual time step, using RAMAS Metapop (Akçakaya, Burgman \& Ginzburg 1997). 
Productivity or fecundity was calculated, each year, as the number of fledglings divided by the total number of females, including both females with brood and broodless females observed during summer counts (post-breeding census). In the simulation process we included the number of daughters per female (i.e. maternity or fertility) duly corrected by the sex ratio for fledglings ( 0.69 male fledglings per adult female) estimated by Moss et al. (2000). The standard deviation of this parameter was calculated using the Delta method to combine the standard deviations of productivity and sex ratio (Seber 1982). To avoid possible biases due to small sample size we only considered those annual productivity estimates based on a minimum of 10 flushed females (Moss et al. 2000; Summers et al. 2004).

There are no annual survival probability estimates for our study population. Regarding adult female annual survival, literature provides a range of possible values from 0.63 in Scotland (Moss et al. 2000) to 0.82 in the Jura Mountains in France (Leclercq 1987). Intermediate values were obtained for Finland (0.71 in Lindén 1981) or Germany (0.65 in Storch 1993). With respect to immature survival, the availability of estimates was lower and variable depending on whether immatures were considered to be chicks, juveniles or fledglings in each study. For fledglings, values ranged from 0.50 in Scotland (Moss et al. 2000) to 0.16 in the Jura Mountains in France (Leclercq 1987).

\section{Parameter combinations to set the baseline matrix}

To deal with parameter choice uncertainty, we established a protocol to determine which combination of parameters $\left(\operatorname{Prod}, S_{F l}, S_{A d}\right)$ would provide the same $\lambda$ than that calculated from our empirical adult densities. This combination was used to parameterize what we called the baseline matrix, used for subsequent modelling. On the basis of our fixed 
empirical average population productivity value, we searched for the possible values that both survival rates $\left(S_{F l}\right.$ and $\left.S_{A d}\right)$ could take to achieve the observed empirical $\lambda$ value. For adult survival we considered all values ranging from 0.62 to 0.82 . These values together with productivity, allowed us to calculate what might be the survival of fledglings in each case. Fledgling survivals lower than 0.16 or higher than 0.50 (limits from the literature) were discarded as biologically meaningless. Thus, we obtained two biologically sensical combinations of parameters (Table 1) which accounted for the observed population trend since 1989. To choose the final combination to be used in our modelling, elasticities were calculated for the three vital rates included in each combination. We employed these elasticities to ensure that the choice of a baseline matrix or another, from among the two candidates, would not result in subsequent biases in modelling. This was done by means of the software and environment R (http://www.r-project.org/).

\section{Initial population abundances, stochasticity and density dependence}

Our observed population trend was based on densities, thus we had to back-transform them into absolute abundances to allow modelling. We did so by multiplying each annual density by approximately the core surface area currently occupied by the capercaillie in the study zone $(5,360$ has). The initial number of adult females was obtained using the average adult sex ratio observed in the route censuses. The average observed proportion of fledglings per adult was used to obtain the initial number of fledglings. To calculate the number of female fledglings we used the ratio provided by Moss et al. (2000).

After an initial simulation including demographic stochasticity, we finally excluded it from our simulations as its effect was found to be negligible. We incorporated environmental stochasticity only in productivity since this was the only vital rate for which we knew its standard deviation from field data for the study population. In addition, 
capercaillie productivity is known to be highly variable from year to year, mainly due to variable temperature and rain conditions during the incubation and hatching periods (Moss, Oswald \& Baines 2001). In our simulations of environmental stochasticity, productivity was sampled randomly from a lognormal distribution, with the mean and standard deviation estimated from procedures explained above. Density-dependent effects were not modelled because no evidence of them acting on any vital rate has been detected in the study population so far, and these are poorly known for the species (Grimm \& Storch 2000).

\section{Modelling management scenarios}

We explored two management actions included in the capercaillie conservation strategies in Spain

(http://www.mma.es/portal/secciones/biodiversidad/especies_amenazadas/estrategias_plane

s/index.htm), and their combination: a) the reinforcement of the current population by means of the captive-breeding and release of individuals, b) the removal of terrestrial mesopredators and c) the combination of reinforcement and removal. Management scenarios were modelled for an 8 year period, starting in 2010. This is the duration of two consecutive hypothetical LIFE+-EU projects (http://ec.europa.eu/environment/life). The initial population size for the prospective simulations was the value predicted by the retrospective baseline model for the year 2010. Prospective simulations were carried modifying the matrix parameters of the baseline model required to simulate each scenario. We maintained the same stochasticities as in the retrospective analysis. In addition, we were interested in the amount in which vital rates needed to be improved to achieve, at least, population stability $(\lambda=1)$.

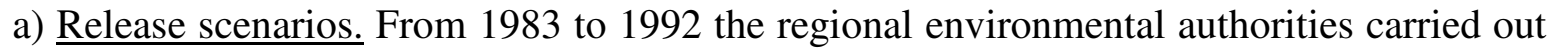
a program of release of captive-bred capercaillies (García-Ferré, unpublished report). The 
approximate number of birds released each year was 15. Released capercaillies were 3 months old at release (fledglings), and the sex ratio of releases depended on bird availability. Releases were done in September. The available information was mainly descriptive and showed that approximately $65 \%$ of the birds died during the first two months after release and less than $16 \%$ managed to survive one year in the wild. Newly released birds were predated in ca. $50 \%$ of the cases. These numbers illustrated that the mortality of newly released birds was very high, so we had to penalize somehow the survival rates of immediately released birds ("cost of release" hereon) in our simulations. The information from the former program did not include annual survival estimates corrected by the probability of recapture for released birds, so it could only be used as an raw orientation. Since there is no further information about the magnitude of the cost of release of captive-bred capercaillies, or other closely related species, in the literature, we decided to use the cost of release estimated for another herbivore ground-nesting prey bird species, the crested coot (Fulica cristata) (Tavecchia et al. 2009). Coot survival during the first year after release experimented a $79 \%$ decrease. We initially considered the release of both fledglings and adults. We applied proportionally the cost of release to both capercaillie fledgling and adult survival rates. Survival rates affected by the cost of release were 0.10 and 0.17 for the releases of fledglings and adults, respectively. We modelled this scenario by adding a third stage to the baseline matrix, the released birds (Figure 1). We also changed bird abundances in each time step of the simulation process to account for the incorporation of the newly released birds to population numbers. Preliminary results showed that the release of juvenile birds resulted in a negligible effect on the population, due to their low intrinsic survival rate together with the high cost of release. Therefore, we only modelled the release of adult females and in variable number: 15, 30 and 45 annually, 
being the latter amount a possible upper limit for the availability of captive-bred capercaillie to be released at any time (Marshall \& Edwards-Jones 1998).

b) Predator removal scenarios.

We took advantage of an ongoing experimental program of removal of terrestrial mesopredators carried out by the environmental authorities, to quantify the effect of predation by terrestrial carnivores on capercaillie vital rates. Two controls (C) and one treatment (T) areas were set. Individuals were trapped and translocated (except for red foxes which were legally euthanized) during the spring and early summer, to try to induce a positive effect on capercaillie laying, hatching and fledging success. This program is providing the first initial results after three years of continued implementation starting in 2008 (own unpublished data). Within an adaptive management framework we explored whether observed changes in productivity (between treatment and control areas during the three years of the experiment), if any, could affect the population growth rate or not. The overall effect size was calculated as the standardized mean difference in productivity between pairs of treatment and control (duly weighted by sample size), using a random effects meta-analysis approach by means of the software Comprehensive Meta-Analysis v12 (Englewood 2000). The survival rates in the matrix were kept the same as in the baseline model since, in the absence of information, we were not able to assign any possible relationship between the removal of carnivores and improvements in the survival rates of the species.

c) Combination of predator removal and captive-bred releases.

We simulated the combined effect of the two previous management scenarios because many previous attempts to reinforce wild capercaillie populations using captive-bred individuals have failed because of high predation rates acting on the inexperienced birds 
(Klaus 1997, 1998; Storch 2007). However, in the absence of data on the possible increase in survival in the newly released birds due to meso-predator removal, the combination of both management strategies was done in an additive way. These scenarios were modelled by including in the matrix structure the possible changes in productivity obtained from removal field experiments and the reduced survival rates of released birds. Again, initial abundances were modified in each step to simulate the contribution of introduced birds.

\section{Results}

\section{Population growth rate and trend}

Empirically-obtained density data from 1988 to 2010 are showed in Figure 2, where the values discarded for further calculations due to previous filtering (years 1988, 1990, 1991, 1992 and 1997) suggest the same trend than the rest of the time series, except for 1995 which is considered to be an outlier. The observed population growth rate between 1989 and 2010 was 0.96 (4\% annual decrease). The population moved from a density of 0.11 adults per hectare to 0.04 in that period. A general linear model showed that the slope of the regression of density with time was negative and its departure from zero was statistically significant (slope estimate $=-0.0025 ; 95 \%$ confidence interval of the slope: $(-0.0035,-$ $0.0016)$.

\section{Baseline model and retrospective simulation}

None of the combinations that included an adult survival lower than 0.79 were considered to be possible, from a biological perspective, given that they implied survival rates for fledglings much higher than those mentioned in the literature. The combinations that led to a deterministic lambda of 0.96 are presented in Table 1. Provided that the proportion 
between the relative contributions of each parameter to the population growth rate remained constant (approximate proportion 5:1:1 for $S_{A d}, S_{F l}$ and Prod), we were confident that model choice would not affect the main results. We arbitrarily chose combination defined by $S_{A d}=0.82$ and $S_{F l}=0.48$ to parameterize the baseline matrix.

Figure 3 shows the fit of the baseline model (baseline matrix+environmental stochasticity) to the overall trend observed in the population, with almost all the observed points being included within the simulated mean trajectory $95 \%$ confidence bounds, except for the unusually low data recorded in 1994. The stochastic lambda calculated from this model was $0.96(\mathrm{SE}=0.06)$.

From the baseline matrix, we estimated what should the improvement in any of the vital rates be to lead to population stability (that is, to a deterministic lambda=1) (Table 2). Our sensitivity analysis, indicated that the only vital rate susceptible of improvement to at least reaching population stability in our study is productivity, considering that values of survival in our modelling are already in the upper limits of the values in the literature. However, any combined increase in recruitment parameters (productivity+fledgling survival), that summed up to $33 \%$ may also lead to stabilization.

\section{Prospective simulations: Management scenarios}

The results of the terrestrial meso-predator removal experiment are presented in Table 3. The overall effect size was 0.14 . This meant that this strategy increased by $36 \%$ and $32 \%$ the mean productivity in the treatment area with respect to controls 1 and 2 , respectively. The fact that the $95 \%$ confidence interval of this estimate included the value zero $(-0.18,0.46)$ was most likely due to the low number of treatment-control pairs available for meta-analysis. However, we used the overall effect size for our modelling as 
the best estimate available so far of the effect of the removal experiment on capercaillie productivity within an adaptive management approach to inform future conservation actions. Keeping this in mind, and applying the precautionary principle, we decided to model only the less optimistic of the situations (the $32 \%$ of increase on total productivity). We converted this increase into the female portion of the fledglings, which implied a change in the number of female fledglings per female from 0.30 to 0.40 , for the subsequent modelling. For our simulations we assumed that the effect in 2010 was maintained during the 8 years of simulated management. The results from the simulation of the eight possible management scenarios established (i.e. no action, meso-predator removal, three scenarios of release (15/30/45 annual release of adults) and the three combined scenarios) are shown in Table 4 and Figures 4 and 5. The stochastic population growth rate for scenarios 2 to 4 , involving bird releases, did not change but released birds contributed to population numbers. Therefore, and in order to show the magnitude of the effect of releases on population size at the end of the management period we examined the simulated number of adult females at that time (Table 4). If we take into account not only the average number of adult females at the end of the management period but its $95 \%$ confidence intervals (Figure 5), the only strategies whose $95 \%$ CIs do not overlap with the $95 \% \mathrm{CI}$ of the non-action scenario were the combinations of meso-predator removal together with the release of either 15, 30 or 45 adults annually. Hence only these strategies can be considered to be effective.

With respect to the expected population trend, in Figure 4 we show that scenarios 2 and 3 do not succeed in reversing the declining trend of the population, while predator removal does (scenario 1 , stochastic lambda $=0.99, \mathrm{SD}=0.06$ ). The rest of simulated 
scenarios (from 4 to7) indicate that the population could increase, at least, until the end of the management period.

\section{Discussion}

The low observed rate of decline (4\% annual decline) coincides with the annual decrease estimated for capercaillies recently in Finland (Sirkiä et al. 2010), and it can be framed within the general decline of capercaillie populations throughout Europe (Storch 2007). The reduction is more intense in western and central Europe, where several local extinctions have occurred recently (Storch 2007). We caution that the transformation of our density estimates into number of capercaillie females must not be interpreted as real absolute population size estimates, as they depend on the estimate of surface area we have used as the species current range in the study area. It is important to make clear that we were interested in modelling the population trend (i.e. comparable estimates of relative abundance from year to year) not the absolute numbers, which are not confidently known. We succeeded in this respect since the $95 \%$ confidence intervals of our simulations bracketed most empirically-derived data.

Not all the simulated management scenarios were able to reverse the declining trend of the population, although all of them caused relative ratios of increase ranging from 1.15 to 2.35 in the simulated number of adult females. Only the release of 45 adult females per year could compensate for current population losses. Certainly we have imposed a strong cost of release (around 80\%) to all scenarios involving the release of captive-bred birds, but this is probably not very unlikely because data from the past experience of release of captive-bred individuals in the area showed that only $16 \%$ of birds released survived more 
than one year in the wild. In fact the IUCN Grouse Specialist Group strongly discourages reintroduction and reinforcement attempts for capercaillie because chances of success are remote for this species (Storch 2007).

Also, according to our simulations the removal of terrestrial meso-carnivores may lead to the stabilization of the capercaillie population, contrary to the review by Lavers, Wilcox \& Donlan (2010) who found that in ca. 30-67\% of the bird species studied the predicted increase in productivity due to predator removal alone was insufficient to reverse the predicted population declines. The duration of other removal experiments in the literature has been longer than 3 years (e.g. 6 years in Kauhala, Helle \& Hello 2000 and Baines, Moss \& Dugan 2004 and 8 years in Marcström, Kenward \& Engren 1988), what may help to explain why the $95 \%$ confidence interval of the overall effect size of the removal experiment included the value zero, in addition to the scarcity of replications. We analyzed the data after 3 years of experiment to inform managers on the viability (or lack of it) of continuing implementing such an experiment for a longer time.

However, if we were to focus only on the average number of females obtained by simulation after the period of management, our expectations could be too optimistic. Thus, we evaluated the efficacy of the different management scenarios by using the $95 \%$ confidence intervals of the abundance estimates. That way, the only strategies which can be said to be effective are the combined ones (i.e. removal+the three release scenarios). Environmental authorities should assess the economics of these combined strategies, because the cost of predator control must be added to the cost of captive breeding.

The positive effect of removals on the population could be much greater if there was an effect on adult survival rates, the vital rate with a higher elasticity. Similar previous 
experiences (Marcström, Kenward \& Engren 1988; Kauhala, Helle \& Hello 2000; Baines, Moss \& Dugan 2004) showed that predator control may have a positive effect on capercaillie breeding success, although none of them modelled its subsequent implications on population dynamics. The effect of predator removal on adult numbers was not so evident for Kauhala et al. (2000), despite it increased the counts of adults after two years of predator removal in islands of Sweden (Marcström, Kenward \& Engren 1988). Of the 23 radio-marked capercaillies in an ongoing experience in our study area since 2007, six of them $(26 \%)$ were killed by predators (four females and two males). Although it cannot be stated with certainty if they had died because of other reasons previously and they were subsequently predated, this shows that predation also affects adult capercaillie survival and not only offspring survival. As deduced from the value of the parameters in the literature, it does not seem likely to increase adult survival rates any further. Hence, adult mortality caused by predators is most likely compensatory, rather than additive in our population. All our results point towards the need of focussing on improving recruitment (productivity+fledgling survival) to enhance the capercaillie population in the Pyrenees.

\section{Exploration of ultimate causes of predation}

In all modelled scenarios the population came back to the original declining trend as soon as management ceased, as a consequence of our modelling procedure. However, this is likely to happen if the causes that are producing the current decline are not removed. Under the current circumstances, the releases may constitute only a temporal buffer to the loss of birds originated by the ultimate causes. According to the literature, the removal of predators seldom has had self-sustainable effects over time (Reynolds \& Tapper 1996; Smith et al. 2010), although, short-term control of predators may allow prey species to achieve 
permanently higher densities when predator-prey dynamics is subjected to a predator pit situation (Evans 2004).

Among the principal threats for the species mentioned by the IUCN Specialist Group (Storch 2007), pollution, collisions and exploitation, can be discarded as affecting our study population. The effect of other causes such as small population size, habitat degradation, human disturbance, predation and climate change is still to be studied. However, the study area, as most of the mountain areas in southern Europe, has experienced strong socio-economical changes over the last 60 years, characterized by a strong depopulation trend and abandonment of traditional land uses, such as the cease of the silvicultural practices (Lasanta-Martínez, Vicente-Serrano, \& Cuadrat-Prats 2005). Synchronously, predator removing practices, traditionally, rewarded economically by the Spanish Government, were prohibited (Martínez-Abraín et al. 2008). Some studies have shown the negative effect of fragmentacion-edge effects on capercaillie, increasing predation risk (Storch, Woitke \& Krieger 2005), although little is known about the effect of forest densification. In this sense, a recent study by Ameztegui, Brotons \& Coll (2010) shows that mountain pine forests, the main habitat for capercaillies, has almost doubled its density (trees/ha) in the Catalan Pyrenees between 1956 and 2006. This densification may influence two of the most commonly cited factors in relation to the general decline of capercaillie populations: a) predation rates, and b) bilberry cover.

In much of the study area the abundance of big game species (i.e. roe deer, fallow deer -an introduced species- and wild boar) has greatly increased in the last decades, as it has been the case in most of the Iberian Peninsula (Gortázar et al. 2002; Rosell 2001; Carranza 2002). It is seems reasonable that the larger the population the higher the number of carcasses in the wild caused by heavy snowfalls in these mountains. Moreover, during 
the hunting season (October-February), hunters usually collect only their hunting trophies and leave behind the main portion of the carcasses. All these remains most likely serve as food for meso-carnivore guild during the winter season, when food availability typically is lower. In the absence of top predators and with the possible subsidization of meso-predators by hunting discards, this guild may be impacting on scarce prey, such as capercaillie (Gompper \& Vanak 2008). In addition, several studies have shown that overabundant ungulate populations may also have a substantial detrimental effect on capercaillie and other closely related species, such as black grouse, by damaging ground vegetation, mainly bilberry (Pollo et al. 2003; Baines 1996).

As applied implications, since the management target is to prevent or correct a possible hyperpredation, the removal of predators or the release of captive-bred birds would only address proximate causes. We believe that these strategies should be implemented as urgency measures while longer term strategies, for the management of predation rather than predators, are implemented. In this sense, the reduction of wild ungulate numbers may have a double effect, reducing meso-predator numbers and preventing bilberry overgrazing. Similarly, the removal of hunting remains and of any other source of subsidization, could also have similar long-lasting effects. Also, the recovery of former pine densities could reduce the impact of predation (i.e. increasing chances to escape from terrestrial predators) and benefit the growth of bilberry, which is prevented within too dense forests.

\section{Acknowledgements}

G. Tavecchia and D. Doak helped with the modeling process. Authors are thankful to D. Oro, R. Moreno-Opo, M. Martínez-Jauregui and A. San-Miguel for their useful comments 
and to F. García Domínguez, J. Muñoz-Igualada, J. Piqué and A. Roura for their contribution to the development of the project. MFO was supported by a pre-doctoral contract by Universidad Politécnica de Madrid and participated in the project "Effects of predation on the Pyrenean Capercaillie population" carried out by Ministerio de Medio Ambiente y de Medio Rural y Marino of the Government of Spain in collaboration with Departament de Medi Ambient i Habitatge (Generalitat de Catalunya). AMA by a JAE post-doctoral contract of CSIC.

\section{References}

Akçakaya, H.R., Burgman, M.A. \& Ginzburg, L.R. (1997) Applied population ecology using RAMAS® Ecolab. Applied Biomathematics, New York.

Ameztegui, A., Brotons, L. \& Coll, L. (2010) Land-use changes as major drivers of mountain pine (Pinus uncinata Ram.) expansion in the Pyrenees. Global Ecology and Biogeography, 19, 632-641.

Baines, D. (1996) The implications of grazing and predator management on the habitats and breeding success of black grouse Tetrao tetrix. Journal of Applied Ecology, 33, 54-62.

Baines, D., Moss, R. \& Dugan, D. (2004) Capercaillie breeding success in relation to forest habitat and predator abundance. Journal of Applied Ecology, 41, 59-71.

Beck, B.B. (1995) Reintroduction, Zoos, Conservation, and Animal Welfare. In: Norton, B.G., Hutchins, M., Stevens, E.F., Maple, T.L. (Eds.), Ethics on the Ark. Smithsonian Institute Press, Washington, pp. 155-163. 
Bino, G., Dolev, A., Yosha, D., Guter, A., King, R., Saltz, D. \& Kark, S. (2010) Abrupt spatial and numerical responses of overabundant foxes to a reduction in anthropogenic resources. Journal of Applied Ecology, 47, 1262-1271.

Bosch, M., Oro, D., Cantos, J.F. \& Zabala, M. (2000) Short term effects of culling on the ecology and population dynamics of a yellow-legged gull colony. Journal of Applied Ecology, 37, 369-385.

Carranza, J. (2002) Cervus elaphus Linnaeus, 1758. Atlas de los Mamiferos Terrestres de España (eds L.J, Palomo \& J. Gisbert), pp. 310-313. Dirección General de Conservación de la Naturaleza-SECEM-SECEMU, Madrid.

Connolly, G.E. (1978) Predators and predator control. Big game of North America (eds J. L. Schmidt \& D. L. Gilbert), pp. 369-394. Stackpole, Harrisburg, Pennsylvania, USA.

Englewood, N.J. (2000) Comprehensive Meta-Analysis. Biostat.

Evans, K.L. (2004) The potential for interactions between predation and habitat change to cause population declines of farmland birds. Ibis, 146, 1-13.

Fischer, J. \& Lindenmayer, D.B. (2000) An assessment of the published results of animal relocations. Biological Conservation, 96, 1-11.

Fletcher, K., Aebischer, N.J., Baines, D., Foster, R. \& Hoodless, A.N. (2010) Changes in breeding success and abundance of ground-nesting moorland birds in relation to the experimental deployment of legal predator control. Journal of Applied Ecology, 47, 263-272. 
Genovart, M., Negre, N., Tavecchia, G., Bistuer, A., Parpal, L. \& Oro, D. (2010) The young, the weak and the sick: Evidence of natural selection by predation. PLoS ONE, 5, e9774.

Gompper, M.E. \& Vanak, A.T. (2008) Subsidized predators, landscapes of fear and disarticulated carnivore communities. Animal Conservation, 11, 13-14.

Gortázar, C., Herrero, J., Villafuerte, R. \& Marco, J. (2000) Historical examination of the status of large mammals in Aragon, Spain. Mammalia, 64,411-422.

Grimm, V. \& Storch, I. (2000). Minimum viable population size of capercaillie Tetrao urogallus: results from a stochastic model. Wildlife Biology, 6, 219-225.

Hewitt, G. (1999) Post-glacial re-colonization of European biota. Biological Journal of the Linnean Society, 68, 87-112.

Igual, J.M., Tavecchia, G., Jenouvrier, S., Forero, M.G. \& Oro, D. (2009) Buying Years to Extinction: Is Compensatory Mitigation for Marine Bycatch a Sufficient Conservation Measure for Long-Lived Seabirds? PLoS ONE, 4, e4826.

Kauhala, K., Helle, P. \& Hello, E. (2000) Predator control and the density and reproductive success of grouse populations in Finland. Ecography, 23, 161-168.

Klaus, S. (1997) Breeding and releasing projects for capercaillie in Germany. Grouse News, 14, 4-7.

Klaus, S. (1998) Breeding and releasing projects for capercaillie in Germany. Reintroduction-News/IUCN, 16, 7-9.

Lasanta-Martínez, T., Vicente-Serrano, S.M. \& Cuadrat-Prats, J.M. (2005) Mountain Mediterranean landscape evolution Land-use changes drive Pinus uncinata 
expansion caused by the abandonment of traditional primary activities: a study of the Spanish Central Pyrenees. Applied Geography, 25, 47-65.

Lavers, J.L., Wilcox, C. \& Donlan, C.J. (2010) Bird demographic responses to predator removal programs. Biological Invasions, 12, 3839-3859.

Leclercq, B. (1987) Ecologie et dynamique des populations du grand tétras (Tetrao urogallus major L.) dans le Jura français. PhD thesis, Faculté des Sciences de la Vie, Université de Bourgogne.

Linden, H. (1981) Estimation of juvenile mortality in the capercaillie, Tetrao urogallus, and the black grouse, Tetrao tetrix, from indirect evidence. Finnish Game Research, 39, 35-51.

Lombardi, L., Fernández, N. \& Moreno, S. (2007) Habitat use and spatial behaviour in the European rabbit in three Mediterranean environments. Basic and Applied Ecology, 8, 453-463.

Ludwig, D., Mangel, M. \& Haddad, B. (2001) Ecology, Conservation, and Public Policy. Annual Review of Ecology and Systematics, 32, 481-517.

Macdonald, D.W., Mace G.M. \& Barretto, G.R. (1999) The effects of predators on fragmented prey populations: a case study for the conservation of endangered prey. Journal of Zoology London, 247, 487-506.

Marcström, V., Kenward, R.E. \& Engren, E. (1988) The impact of predation on boreal tetraonids during vole cycles: an experimental study. Journal of Animal Ecology, 57, 859-872. 
Marshall, K. \& Edwards-Jones, G. (1998) Reintroducing capercaillie (Tetrao urogallus) into southern Scotland: identification of minimum viable populations at potential release sites. Biodiversity and Conservation, 7, 275-296.

Martínez-Abrain, A., Crespo, J., Jiménez, J., Pullin, A., Stewart, G. \& Oro, D. (2008) Friend or foe: Societal shifts from intense persecution to active conservation of top predators. Ardeola, 55, 111-129.

Moleón, M., Almaraz, P. \& Sanchez-Zapata, J.A. (2008) An Emerging Infectious Disease Triggering Large-Scale Hyperpredation. PLoS ONE, 3, e2307.

Moss, R., Oswald, J. \& Baines, D. (2001) Climate change and breeding success: decline of the capercaillie in Scotland. Journal of Applied Ecology, 70, 47-61.

Moss, R., Picozzi, N., Summers, R.W. \& Baines, D. (2000) Capercaillie Tetrao urogallus in Scotland-demography of a declining population. Ibis, 142, 259-267.

Pollo, C.J., Robles, L., García-Miranda, A., Otero, R. \& Obeso, J.R. (2003) Variaciones en la densidad y asociaciones espaciales entre ungulados silvestres y Urogallo cantábrico. Ecología, 17, 199-206.

Reynolds, J.C. \& Tapper, S.C. (1996) Control of mammalian predators in game management and conservation. Mammal review, 26, 127-155.

Robles, L., Ballesteros, F. \& Canut, J. (eds) (2006) El urogallo en España, Andorra y Pirineos franceses. Situación actual. SEO/BirdLife. Madrid.

Rosell, C. (2001) Los ungulados y los ecosistemas forestales: los ejemplos del corzo y del jabalí. Conservación de la biodiversidad y gestión forestal. Su aplicación en la 
fauna vertebrada. (eds J. Camprodón, J. \& E. Plana), pp. 377-396. Ediciones de la Universidad de Barcelona. Barcelona.

Sachot, S., Perrin, N. \& Neet, C. (2006) Viability and management of an endangered Capercaillie (Tetrao urogallus) metapopulation in the Jura Mountains, western Switzerland. Biodiversity and Conservation, 15, 2017-2032.

Seber, G.A.F. (1982) The estimation of animal abundance. 2nd edition. Griffin, London UK.

Seddon, P.J., Armstrong, D.P. \& Maloney, R.F. (2007) Developing the science of reintroduction biology. Conservation Biology, 23, 303-312.

Sinclair, A.R.E., Pech, R.P., Dickman, C.R., Hik, D., Mahon, P. \& Newsome, A.E. (1998) Predicting effects of predation and conservation of endangered prey. Conservation Biology, 12, 564-575.

Sirkiä, S., Lindén, H., Helle, P., Nikula, A., Knape, K. \& Lindén, H. (2010) Are the declining trends in forest grouse populations due to changes in the forest age structure? A case study of Capercaillie in Finland. Biological Conservation, 143, $1540-1548$.

Smith, R.K., Pullin, A.S., Stewart, G.B. \& Sutherland, W.J. (2010) The effectiveness of predator removal for enhancing bird populations. Conservation Biology, 24, 820829.

Snyder, N.F.R., Derrickson, S.R., Beissinger, S.R., Wiley, W.J., Smith, S.B., Toone, W.D. \& Miller, B. (1996) Limitations of captive breeding in endangered species recovery. Conservation Biology, 10, 338-348. 
Storch, I. (1993) Habitat use and spacing of capercaillie in relation to forest fragmentation patterns. PhD thesis, University of Munich.

Storch, I. (2007) Grouse: Status Survey and Conservation Action Plan 2006-2010. Gland, Switzerland: IUCN and Fordingbridge, UK: World Pheasant Association.

Storch, I., Woitke, E. \& Krieger, S. (2005) Landscape-scale edge effect in predation risk in forest-farmland mosaics of central Europe. Landscape Ecology, 20, 927-940.

Summers, R.W., Green, R.E., Proctor, R., Dugan, D., Lambie, D., Moncrieff, R., Moss, R. \& Baines, D. (2004) An experimental study of the effects of predation on the breeding productivity of capercaillie and black grouse. Journal of Applied Ecology, 41, 513-525.

Suter, W., Graf, R.F. \& Hess, R. (2002) Capercaillie (Tetrao urogallus) and avian biodiversity: testing the umbrella-species concept. Conservation Biology, 16, 778788.

Tablado, Z., Tella, J.L., Sánchez-Zapata, J.A. \& Hiraldo, F. (2010) The paradox of the long-term positive effects of a North American crayfish on a European community of predators. Conservation Biology, 24, 1230-1238.

Tavecchia, G., Viedma, C., Martínez-Abraín, A., Bartolome, M.A., Gomez, J.A. \& Oro, D. (2009) Maximizing re-introduction success: Assessing the immediate cost of release in a threatened waterfowl. Biological Conservation, 12, 3005-3012.

Vucetich, J.A. \& Waite, T.A. (2003) Spatial patterns of demography and genetic processes across the species' range: Null hypotheses for landscape conservation genetics. Conservation Genetics, 4, 639-645. 
Wolf, C.M., Garland, T. \& Griffith, B. (1998) Predictors of avian and mammalian translocation success: reanalysis with phylogenetically independent contrasts. Biological Conservation, 86, 243-255. 
Table 1. Parameter combinations that led to the observed population growth rate $(\lambda=0.96)$. Productivity (Prod) value 0.30 is the empirical population mean obtained in the field for 1989-2010. $S_{A d}, S_{F l}$ adult and fledgling survival rates. Combinations 1 and 2 are included to illustrate the parameterization process, although they were discarded because they slightly exceed the highest survival probabilities cited in the literature for fledgling females.

\begin{tabular}{|c|c|c|c|c|}
\hline Combination & Prod & $\boldsymbol{S}_{\boldsymbol{A d}}$ & $\boldsymbol{S}_{\boldsymbol{F l}}$ & Elasticities $^{*}$ \\
\hline 1 & 0.30 & 0.79 & 0.54 & $0.15-0.70-0.15$ \\
\hline 2 & 0.30 & 0.80 & 0.51 & $0.14-0.71-0.14$ \\
\hline 3 & 0.30 & 0.81 & 0.48 & $0.13-0.73-0.13$ \\
\hline 4 & 0.30 & 0.82 & 0.45 & $0.13-0.74-0.13$ \\
\hline
\end{tabular}

*Elasticity for $\operatorname{Prod}, S_{A d}$ and $S_{F l}$ respectively 
Table 2. Vital rates increases to reach population stability. All the values are referred to the female part of the population.

\begin{tabular}{|c|c|c|c|}
\hline Vital rate & $\begin{array}{c}\text { Baseline } \\
\text { matrix }\end{array}$ & $\begin{array}{c}\text { Value for } \\
\text { stability }\end{array}$ & $\begin{array}{c}\text { Range of values } \\
\text { from literature }\end{array}$ \\
\hline Productivity & 0.30 & $0.40(\uparrow 33 \%)$ & $0.42-2.12 *$ \\
\hline $\mathrm{S}_{\mathrm{Fl}}$ & 0.45 & $0.60(\uparrow 33 \%)$ & $0.19-0.50$ \\
\hline $\mathrm{S}_{\mathrm{Ad}}$ & 0.82 & $0.86(\uparrow 4.9 \%)$ & $0.63-0.82$ \\
\hline
\end{tabular}

* The lowest value derived from Summer et al. 2000, for Scotland, and the highest derived from Kurki et al. 1997, for Finland. 
Table 3. Preliminary results of the three-year predator removal experiment (2008-2010). Data refer to capercaillie productivity (fledglings/female) in the treatment area and in two control areas (1 and 2). The overall effect size was calculated as the standardized mean difference using a meta-analysis approach. $\mathrm{N}$ : number of detected adult females in that period; Mean and SD: average productivity for that period and its standard deviation.

\begin{tabular}{|l|c|c|c|}
\hline \multicolumn{1}{|c|}{ Zone } & $\boldsymbol{N}$ & Mean & SD \\
\hline Treatment & 42 & 0.57 & 1.33 \\
\hline Control 1 & 26 & 0.38 & 0.90 \\
\hline Control 2 & 46 & 0.43 & 0.81 \\
\hline \multirow{2}{*}{ Overall effect size } & \multicolumn{2}{|c|}{ Mean $=0.14$} \\
\cline { 2 - 4 } & $95 \%$ CI $=(-0.18,0.46)$ \\
\hline
\end{tabular}


Table 4. Average number of females after the implementation of each management scenario (calculated as the arithmetic mean for all the estimates in 1000 replications) and its $95 \%$ confidence interval (CI). Ratio is the quotient between the number of adult females from each management scenario in relation to the no-management scenario.

\begin{tabular}{|c|l|c|c|c|}
\hline \multirow{2}{*}{ Scenario } & \multicolumn{1}{|c|}{ Description } & $\begin{array}{c}\text { Adult } \\
\text { females }\end{array}$ & CI & Ratio \\
\hline 0 & No-management & 100 & $68-132$ & 1.00 \\
\hline 1 & Predator removal & 134 & $92-176$ & 1.34 \\
\hline 2 & Release_15 adults & 115 & $81-150$ & 1.15 \\
\hline 3 & Release_30 adults & 128 & $93-164$ & 1.28 \\
\hline 4 & Release_45 adults & 148 & $111-186$ & 1.48 \\
\hline 5 & Removal +Release 15adults & 171 & $134-208$ & 1.71 \\
\hline 6 & Removal +Release 30adults & 203 & $161-244$ & 2.03 \\
\hline 7 & Removal +Release 45adults & 235 & $192-278$ & 2.35 \\
\hline
\end{tabular}


Figure 1. Life cycle used to build the Lefkovitch stage-based matrix models for capercaillie dynamics. Fl=Fledglings; Ad=Adults; Release=Released adults; Prod=Productivity estimate; $\mathrm{S}_{\mathrm{Fl}}, \mathrm{S}_{\mathrm{Ad}}$ and $\mathrm{S}_{\mathrm{Rel}}=$ Annual survival rates for fledglings, adults and released adults, respectively. The "Release" stage is only used in the management scenarios which include the release of captive-bred birds.

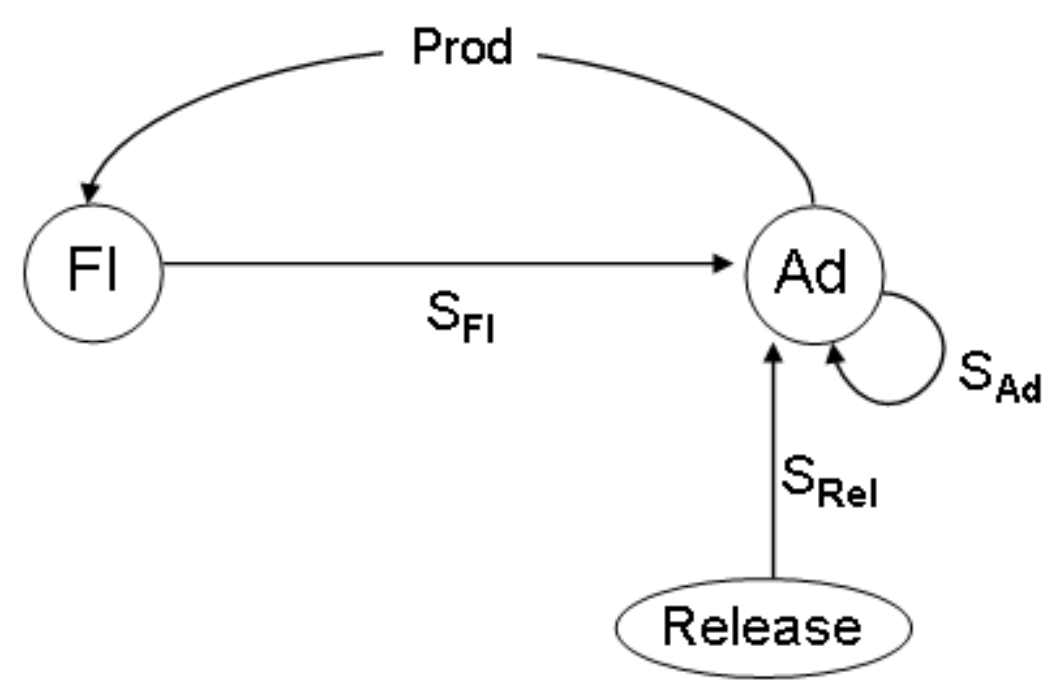


Figure 2. Density of adult capercaillie (males+females), from route census (birds/100 has). Crosses represent the discarded annual estimates, as they were obtained on the base of a field effort lower than 450 has. Triangles represent the values considered to estimate the population trend.

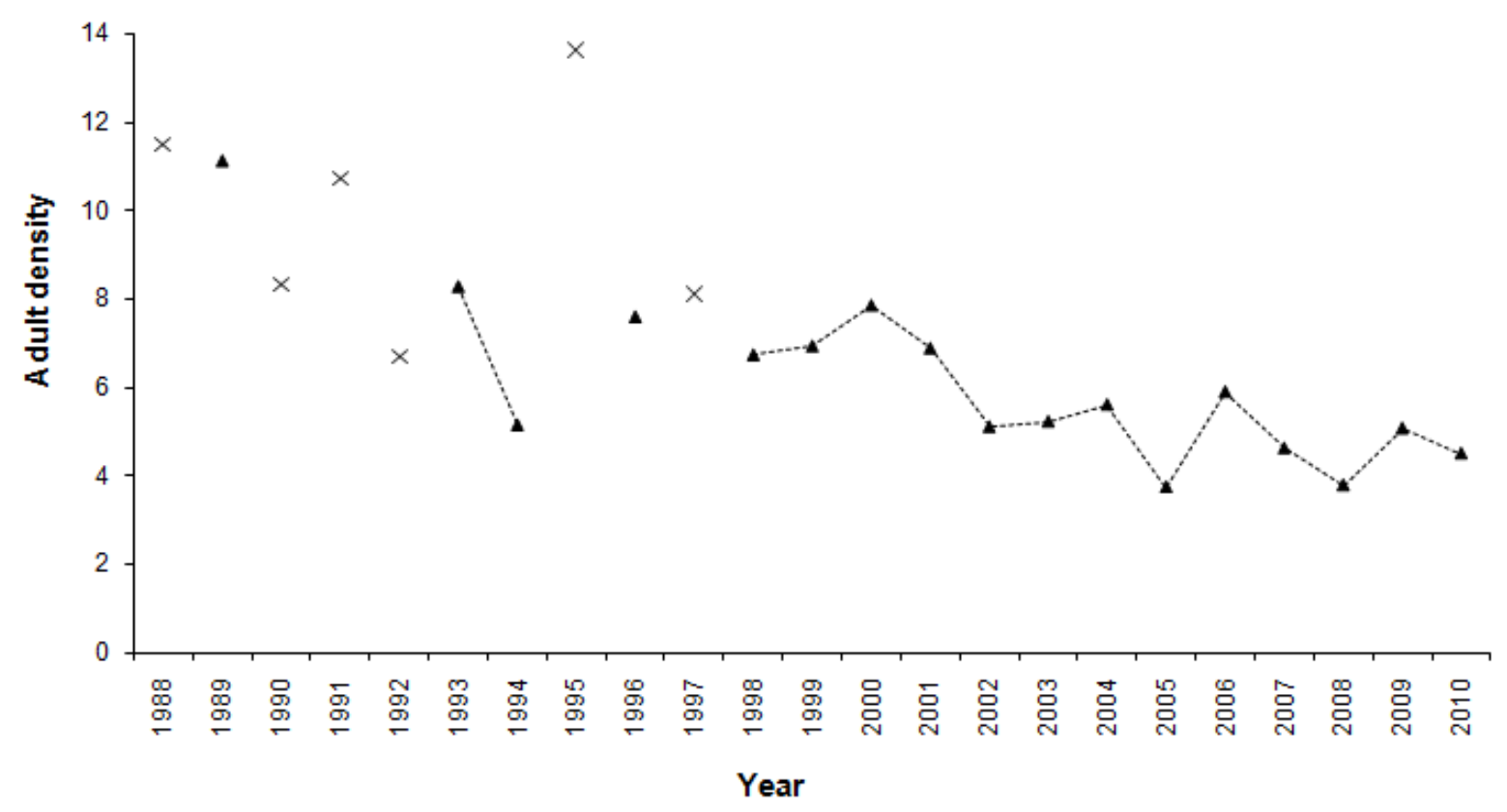


Figure 3. Observed number of adult females (broken line) and average number of adult females simulated by population modelling (continuous line). Vertical bars are 95\% confidence intervals.

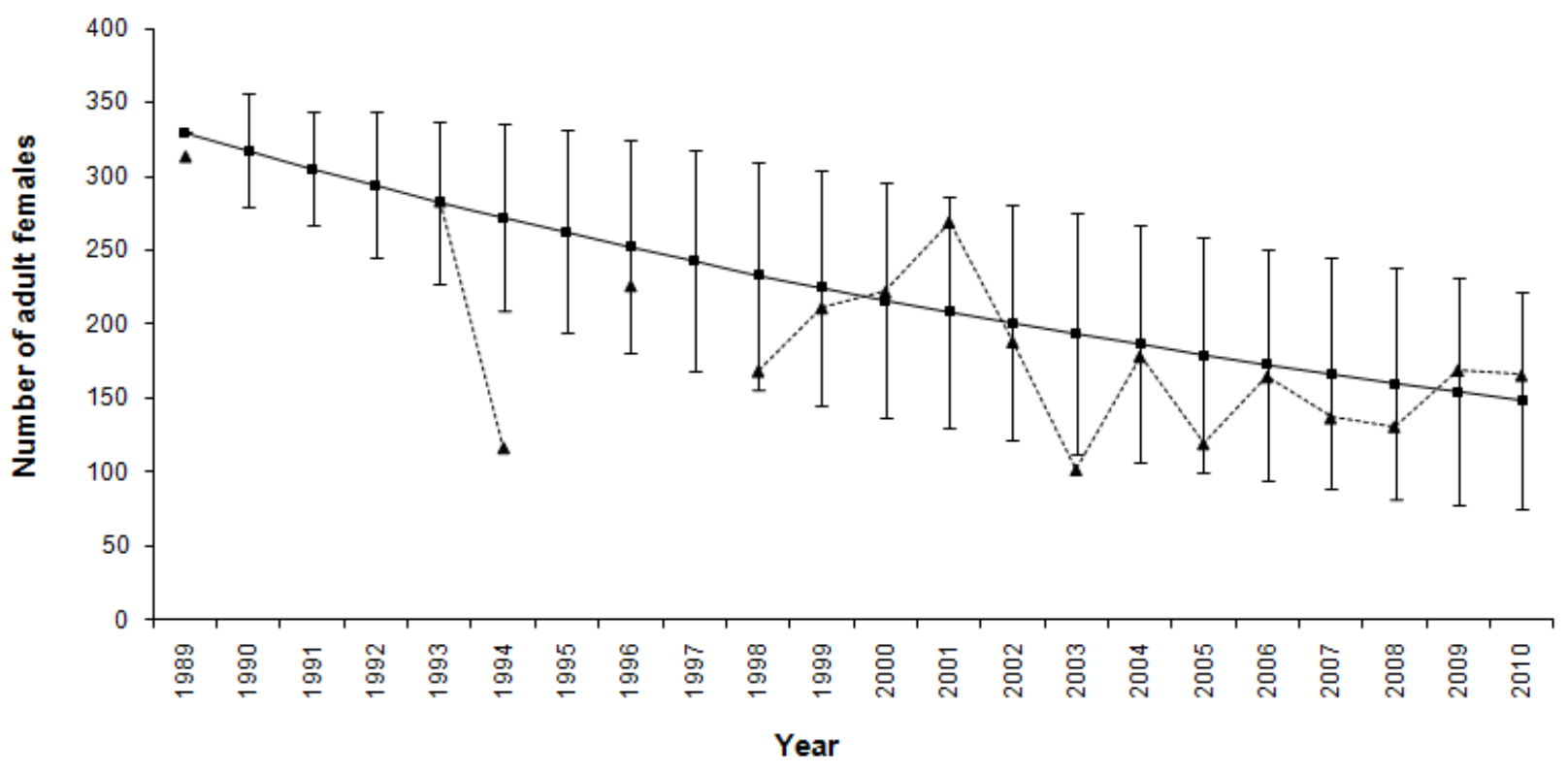


Figure 4. Mean trajectory of simulated management scenarios. Scenarios numeration is:

0_No management action; 1_Predator removal; 2_Release 15 adults; 3_Release 30 adults;

4_Release 45 adults; 5_Removal+release 15; 6_Removal+release 30; 7_Removal+release 45.

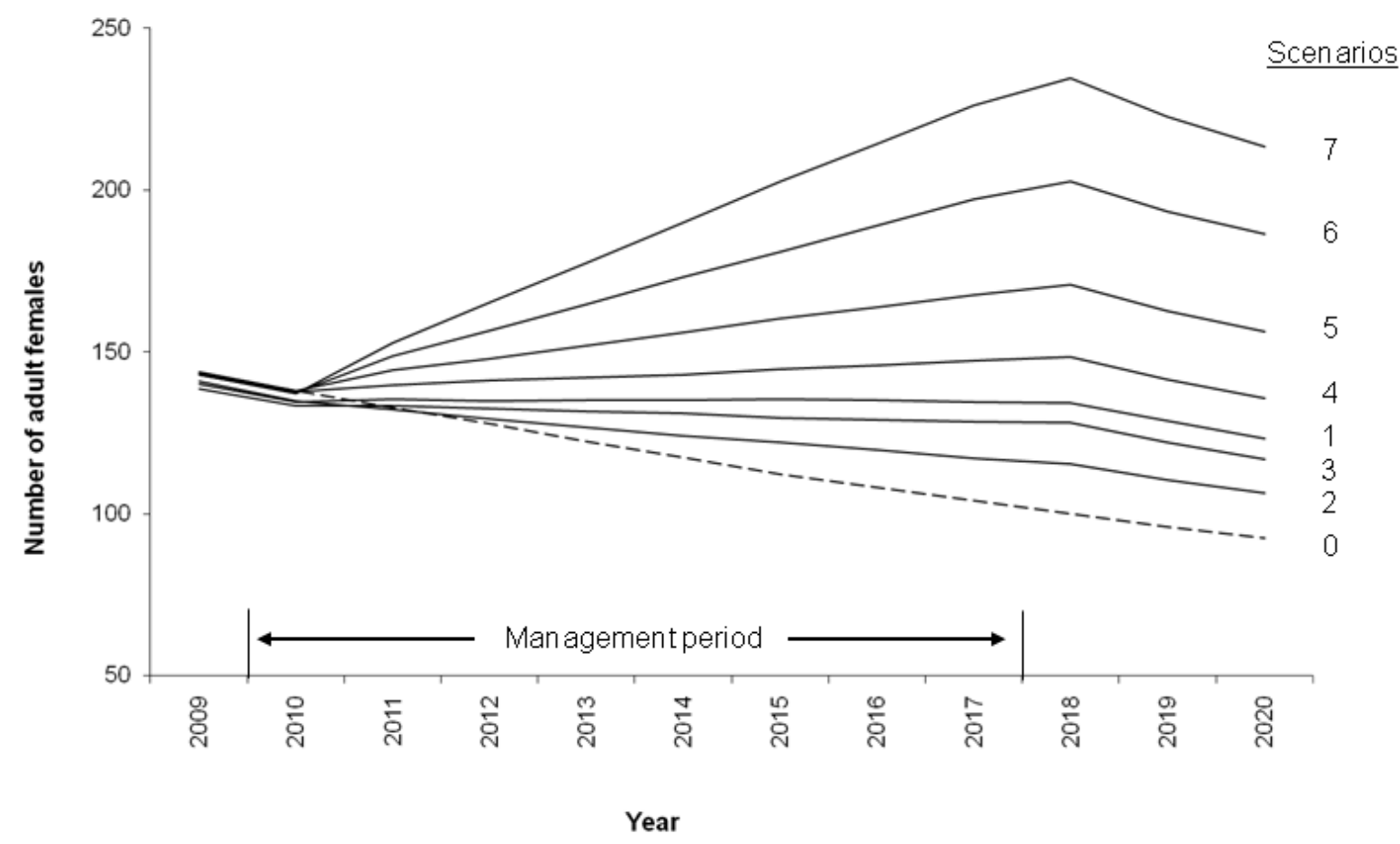


Figure 5. Estimated number of females in each management scenario after management period, and its $95 \%$ confidence intervals.

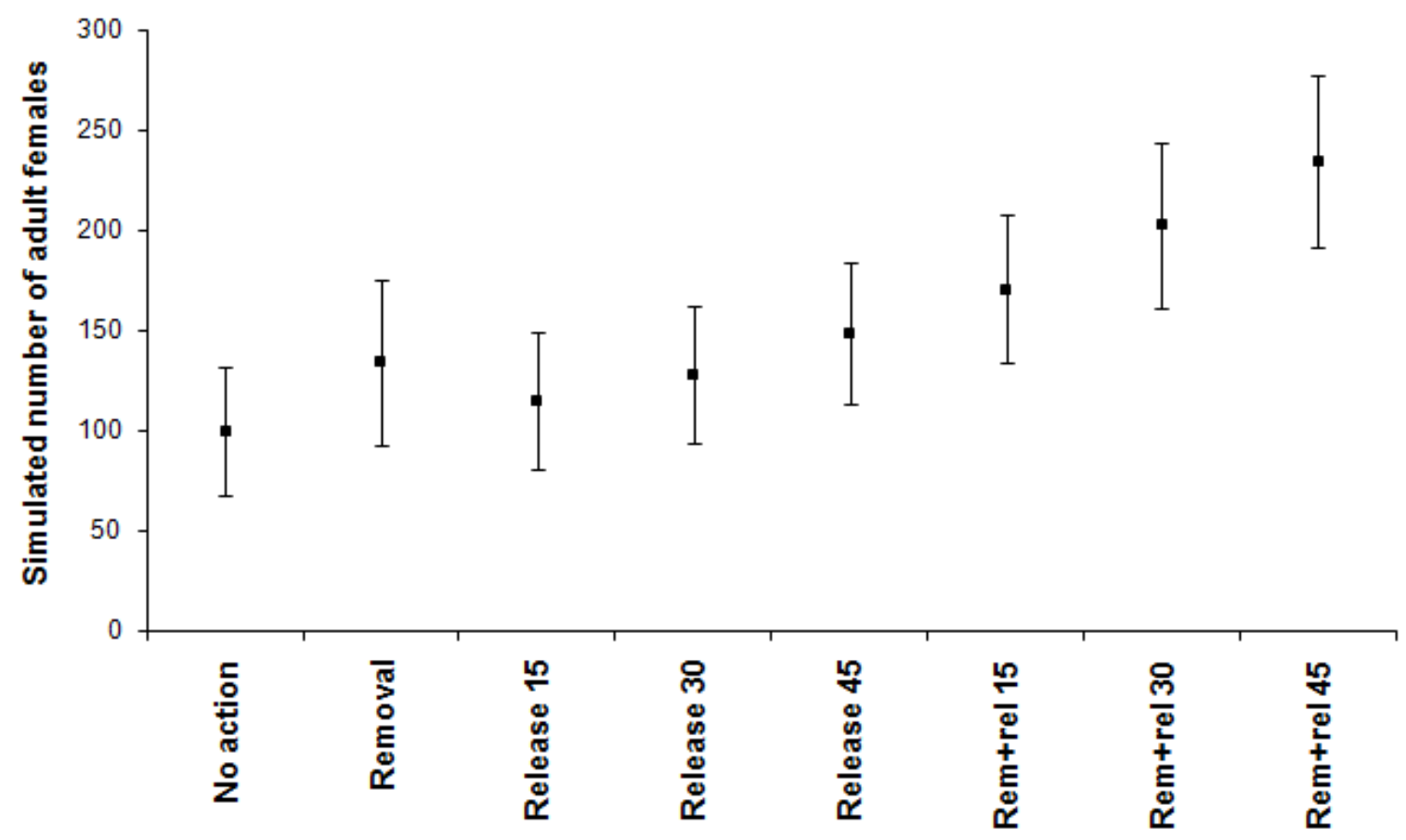

